\title{
Romantismo brasileiro e a "musa popular do Norte"
}

\section{Sílvia Maria Azevedo}

Resumo: Sob o influxo alemão, o culto das tradições populares no sentido da valorização do povo, da exaltação nacionalista ou humanitária do passado foi um dos traços marcantes do romantismo. Além de compactuar com a valorização das origens da nacionalidade, Franklin Távora estará empenhado em acentuar o espírito científico de suas pesquisas sobre o folclore, a exemplo das "Lendas e tradições populares do Norte", publicadas na Ilustração Brasileira, em 1877. Palavras-chave: Franklin Távora, folclore, nacionalismo.

Resumen: Bajo la influencia alemana, el culto a las tradiciones populares como una forma de valorización del pueblo, o sea, la exaltación nacionalista o humanitaria del pasado fue uno de los rasgos marcantes del romanticismo. Más allá de concordar con la valorización de los origenes de la nacionalidad, Franklin Távora se empeñará en profundizar el espíritu científico de sus investigaciones acerca del folclore, como vemos en "Lendas e tradições populares do Norte", publicadas en la Ilustração Brasileira en 1877. Palabras clave: Franklin Távora, folclore, nacionalismo. 
A importância da Guerra do Paraguai, na opinião de várias gerações de historiadores, deve-se, entre outros aspectos, ao fato de ter contribuído para aproximar brasileiros de várias províncias e de diversas origens sociais, com repercussão, inclusive, na produção literária nacional, como vai dizer José Veríssimo:

Pela primeira vez depois da Independência (pois a guerra do Prata de 1851 mal durou um ano e não chegou a interessar a nação) sentiu o povo brasileiro praticamente a responsabilidade que aos seus membros impõem estas coletividades chamadas nações. Ele, que até então vivia segregado nas suas províncias, ignorando-se mutuamente, encontra-se agora fora das estreitas preocupações bairristas do campanário, num campo propício para estreitar a confraternidade de um povo, o campo de batalha. De província a província trocam-se ideias e sentimentos; prolongam-se após a guerra as relações de acampamento. Houve enfim uma vasta comunicação interprovincial do Norte para o Sul, um intercâmbio nacional de emoções, cujos efeitos se fariam forçosamente sentir na mentalidade nacional. A mocidade das escolas, cujos catedráticos se faziam soldados e marchavam para a guerra, alvoroçou-se com o entusiasmo próprio da idade. Os que não deixavam o livro pela espada, bombardeavam o inimigo longínquo com estrofes inflamadas e discursos tonitruantes, excitando o férvido entusiasmo das massas. ${ }^{1}$

Se "houve enfim uma vasta comunicação interprovincial do Norte para o Sul, um intercâmbio nacional de emoções", propiciado pela Guerra do Paraguai, mais evidentes também ficaram as diferenças entre os dois extremos do Brasil, quanto aos melhoramentos introduzidos pelo governo imperial com prioridade para as províncias do Sul, em detrimento das províncias do Norte. As queixas partem, sobretudo, de "homens do Norte", como mostram vários artigos publicados na Ilustração Brasileira (1876-8), periódico carioca ilustrado que veio substituir a folha humorística Semana Ilustrada (1860-76), ambos de propriedade de Henrique Fleiuss.

Um desses "homens do Norte", Fábio Alexandrino de Carvalho Reis, autor do Ligeiro estudo sobre o estado econômico e industrial do Maranhão, opúsculo de 1877 , critica o abandono em que a província vivia mergulhada, apontando como causas do estado de decadência da lavoura do Maranhão a extinção do tráfico de escravos e a imigração de colonos europeus para o Sul. No comentário de A. Ban- 
deira, responsável pela apresentação da obra na seção "Bibliografia" da Ilustração Brasileira, identifica-se o endosso aos reparos de Fábio Alexandrino em relação à política econômica do Império:

O Norte tem ficado sempre menos beneficiado quando se trata de promover os grandes melhoramentos sociais; e se, como cremos, não há desígnio especial nessa espécie de abandono, a coincidência de se encontrarem sempre obstáculos a qualquer grande empreendimento para aquela parte do Império, quando para Sul caminha o Governo à frente dos seus desejos, dá muito que pensar aos homens do Norte, e quase que os faz persuadir de que há, na nossa política, duas bitolas: a da progressão geométrica para o Sul, e da progressão aritmética para o Norte. ${ }^{2}$

Como o Maranhão, outras regiões do Norte do Brasil também se sentiam esquecidas do Imperador, justificativa para a criação da província de São Francisco, proposta apresentada no Senado em 1873, mas que não foi aprovada. Publicado na Ilustração Brasileira, com o título "O Ocidente do Brasil", o texto sem assinatura defende o projeto com o argumento de que o vale do São Francisco estava destinado a ser "um grande empório de riqueza, de indústria, de civilização" do Brasil, por conta da fertilidade das terras às margens do extenso e caudaloso rio. Apesar disso, o "Oeste" vivia ao desamparo dos melhoramentos da civilização. A grande distância em relação ao litoral - lugar de concentração das "comodidades da vida, frutos da civilização, [e] onde [...] o cidadão pode educar seus filhos e acomodar sua família, como permitem os recursos de um país civilizado" - era em grande parte responsável pelo estado de "barbárie" em que permanecia o Ocidente do Brasil:

É mister levar a riqueza, a civilização, que aparece na orla marítima, para o interior desses sertões com o silvo da locomotiva, mas antes disto, é preciso preparar naquelas regiões remotas núcleos para receberem essa civilização, que vai transbordando da beira-mar para o ocidente. ${ }^{3}$

Não somente políticos e fazendeiros clamavam contra o estado de decadência das províncias do Norte, postas à margem do processo de modernização, que o café trouxera para o Rio de Janeiro e São Paulo, mas também homens de letras, como 
Franklin Távora, assíduo colaborador da Ilustração Brasileira. No prefácio ao romance $O$ Cabeleira - "o primeiro manifesto regionalista da literatura brasileira" $-{ }_{,}^{4} \mathrm{o}$ escritor queixa-se do abandono do Norte, imaginando os avanços que a civilização material traria para a região amazônica:

- Que não seria desse mundo [...] se nestas margens se sentassem cidades; se a agricultura liberalizasse nestas planícies os seus tesouros; se as fábricas enchessem os ares com seu fumo, e neles repercutisse o ruído das suas máquinas? Desta beleza, ora a modo de estática, ora violenta, que fontes de rendas não haviam de rebentar? Mobilizados os capitais e o crédito; animados os mercados agrícolas, industriais, artísticos, veríamos aqui a cada passo uma Manchester ou uma New York. [...] O trabalho, o capital, a economia, a fartura, a riqueza, agentes indispensáveis da civilização e grandeza dos povos, teriam lugar eminente nesta imensidade onde vemos unicamente águas, ilhas, planícies, seringais sem-fim. ${ }^{5}$

Este era um sonho (naquela altura) impossível de se transformar em realidade. $\mathrm{O}$ passado glorioso do Norte (ou antes, do Nordeste), centro econômico e cultural do Brasil, no século XVII, estava definitivamente sepultado. Não havia como negar essa evidência, daí a estratégia de Távora de reverter o negativo em positivo, a decadência das províncias do Norte transformando-se em expressão de um Brasil "mais verdadeiro", porque intocado pelos malefícios da civilização destruidora das tradições locais, na transcrição de passagem célebre do prefácio do romance:

As letras têm, como a política, um certo caráter geográfico; mais ao Norte, porém, do que ao Sul abundam os elementos para a formação de uma literatura propriamente brasileira, filha da terra.

A razão é óbvia: o Norte ainda não foi invadido como está sendo o Sul de dia em dia pelo estrangeiro.

A feição primitiva, unicamente modificada pela cultura que as raças, as índoles, e os costumes recebem dos tempos ou do progresso, pode-se afirmar que ainda se conserva ali em sua pureza, em sua genuína expressão. ${ }^{6}$ 
Identifica-se na inter-relação da literatura com o meio físico-social, segundo proposta de Távora, repercussão daquele "bando de ideias novas", na expressão de Sílvio Romero - as doutrinas positivistas de Comte e Littré, o biologismo de Darwin, o evolucionismo de Spencer, o determinismo de Taine, entre elas -, que entraram no Brasil durante os anos 1870, considerados por diferentes historiadores como uma década de inovações, o começo de uma nova era para o Brasil.

Na crítica em forma de carta dirigida a Franklin Távora, "A propósito do Cabeleira", publicada na Ilustração Brasileira, Flávio de Aguiar, um "nortista" como o amigo, retoma as teses centrais do prefácio do romance: "o Norte [...] pode muito bem ter uma literatura sua"; "a observação sem esforço marca diferenças entre norte e sul, diferenças tanto materiais como morais", interpretando igualmente estas diferenças como positivas para a literatura do Norte e negativas para a literatura do Sul. Enquanto naquela são "descritos nossos campos, nossas matas, nossas lavouras, nossos rios, nossas serras, nossas cidades", nesta, "a descrição se cansa com os salões, as toilettes, os bailes e tantos outros assuntos cosmopolitas como estes". Considerações a fundamentar o julgamento taxativo de Flávio de Aguiar: "A literatura do norte é mais brasileira do que a do sul".

A cisão entre o Norte e o Sul do Brasil, que se manifestava tanto no âmbito da política e da economia, quanto no da literatura, refletia a crise do regime monárquico, iniciada com a promulgação da Lei do Ventre Livre, em 28 de setembro de 1871, e agravada com o progressivo desligamento do Imperador quanto à tarefa de governar o Brasil (basta lembrar que na segunda viagem ao exterior, d. Pedro II estivera ausente do país entre maio de 1876 e setembro de 1877), sem deixar de mencionar a chamada "questão religiosa" e os acirrados ataques ao sistema, com a formação do Partido Republicano, que inicia a publicação do jornal A República e lança em dezembro de 1870 o Manifesto Republicano.

Se não havia, na proposta de criação de uma "literatura do Norte", intenção separatista da parte de Franklin Távora, conforme interpretam alguns críticos, é bom lembrar, na sugestão de Cláudio Aguiar, "que no Nordeste e, de forma particular, em Pernambuco, $[\ldots]$ desde o século anterior falavam alto os sentimentos nativistas de movimentos sociais como a Revolução dos Mascates (1710) e as três explosões do século XIX - as Revolução de 1817, 24 e 48". Por sua vez, o herói do romance de Távora, "célebre valentão", não era o que se poderia chamar de modelo de integri-

7 Ilustração Brasileira, n. 9, $1^{\circ}$ nov. 1876, p. 135

8 AGUIAR, Cláudio. Franklin Távora e o seu tempo. São Paulo: Ateliê, 1997, p. 247. 
dade moral, conforme era praxe comportarem-se protagonistas românticos em romances, contos, novelas e peças de teatro em voga no Brasil da época. "Ladrão mui astuto", o Cabeleira e seu bando horrorizaram a província de Pernambuco, no século XVIII, no relato de Fernandes Gama, autor das Memórias históricas da província de Pernambuco, obra de que se valeu Távora para compor o perfil da personagem. Os trovadores pernambucanos do século XviII, que compuseram cantigas alusivas à vida e à morte do Cabeleira, vão cantar não o bandido cruel, mas a vítima que pagou com a forca "os crimes que a bem dizer pertenciam menos a ele do que a outrem", na interpretação de Franklin Távora, que aponta a falta de "instrução e da educação" como responsáveis pela conversão de indivíduo, que poderia ser útil à sociedade, em facínora de "memória execrada, ou lamentável"."

Já o poeta pernambucano Ângelo de S. Paio, no "Canto do Cabeleira", publicado no último número da Ilustração Brasileira, em abril de 1878, interpreta de forma diferente o comportamento do bandido: não há causa nobre, não há honra a ser lavada com sangue a justificar os crimes cometidos pelo Cabeleira e seu bando, tão somente o prazer de matar. Incitado a cantar pelos "valentes camaradas", a trova do Cabeleira faz a apologia da crueldade, na transcrição de alguns versos do poeta pernambucano:

Se o tédio nos busca,/ Se temos tristezas,/ Buscamos torpezas,/ P’ra nos consolar;/ Corremos ao estupro,/ Orgias, incestos;/ E após, eis-nos lestos/ Buscando outro lar!

Se a calma sufoca/ Nas vilas entramos,/ Mil peitos rasgamos/ Co'agudos punhais;/ Nas preces das vítimas,/ No sangue, nos prantos,/ Achamos encantos,/ Que não têm iguais. ${ }^{10}$

Representado pelo Cabeleira, o "herói do mal", no dizer de Samira Campedelli," ${ }^{11}$ este outro Brasil, o do Norte, poderia vir a se constituir em ameaça à unidade política do Império, conquistada na década de 1850, depois de debeladas as rebeliões regenciais. ${ }^{12}$ Por aquela época mesmo, outra serpente estava sendo gerada nas entranhas do próprio sistema. Da província da Bahia chegavam rumores, na notícia divulgada pelo Diário do Rio de Janeiro, de 11 de julho de 1876 , de que um indivíduo de nome

CAMPEDELLI, Samira. Herói do Mal. O Cabeleira de Franklin Távora. 5. ed. São Paulo: Ática, 1997, p. 5-6. 
Antônio Vicente Mendes Maciel, vulgo Antônio Conselheiro, que arrastava atrás de si multidão de seguidores, tinha sido preso porque pregava contra o governo.

O revide, a resposta do Sul ao prefácio de O Cabeleira, virá na forma do editorial de 15 de julho de 1877 da Ilustração Brasileira, "Organize-se o centro", em que se expõe a necessidade da criação de um "centro literário" no país. O momento era dos mais favoráveis "para a constituição das letras no Brasil", uma vez que a "imprensa política", tanto na Corte quanto nas províncias, andava às voltas com disputas partidárias. Às letras cabia, então, "meter na sombra as políticas", e promover a união nacional, conclamada por vários setores da esfera pública: a escola, a imprensa, as associações, os comícios literários, todos à espera da "vida" que havia fugido "dos órgãos políticos, dos comícios eleitorais, das assembleias, do parlamento, do próprio governo". Essa vida, a literatura tinha condições de trazê-la de volta, o que faltava era tão somente a vida literária constituir-se, "aproveitando a esse fim mão hábil e amestrada os elementos que, dispersos quais se mostram ao norte e ao sul, não servem senão para indicar que o Brasil não é de todo ainda um cadáver". ${ }^{13}$

Até mesmo o "diretor do centro" estava escolhido, ou, pelo menos, contava com a aprovação de importantes setores da intelectualidade brasileira. Era o senador Francisco Otaviano de Almeida Rosa, um dos homens mais influentes da chamada geração de 1870, literato, dono de dois importantes jornais da Corte, o Correio Mercantil e A Reforma, mentor da ideia da criação de um centro intelectual de que careciam as letras brasileiras.

Enquanto este "centro" não estava ainda formado (seriam estes os germens da Academia Brasileira de Letras?), cada escritor em particular, "no interesse da ideia que lhe é simpática; do princípio que considera proveitoso para seu país" ${ }^{14}$ - no dizer de outro editorial da Ilustração Brasileira -, concorria para que a "revolução pacífica" tivesse início, quer fosse a fundação de um jornal, a elaboração de um livro, o oferecimento de uma conferência. Era o que faziam os "escritores do Norte", no cumprimento do "dever de levantar ainda com luta e esforços os nobres foros dessa grande região, exumar seus tipos legendários, fazer conhecidos seus costumes, suas lendas, sua poesia, máscula, vívida e louçã”, neste apelo que Franklin Távora deixou registrado no prefácio de $O$ Cabeleira.

Tudo estava por se fazer, a "literatura do Norte" ainda não existia, era necessário criá-la, tarefa possível de ser realizada se houvesse um grupo de escritores, congre- 
gados em torno da ideia de fixar sistematicamente, numa série de romances, como planejaram Távora e Inglês de Sousa, os costumes e a psicologia das províncias setentrionais, a modo de uma cartografia etnográfico-literária do Brasil. No caso do autor de $O$ matuto, o projeto compreendia não apenas a área da criação ficcional, mas também a do ensaio, a exemplo do livro por ele chamado de O Norte (tido até pouco tempo como perdido, mas localizado pelo biógrafo do escritor, Cláudio Aguiar), em que a obra de vinte escritores seria apresentada como expressiva do talento nortista.

$\mathbf{O}$ resgate das lendas e tradições populares era igualmente tarefa urgente, na opinião de Távora, haja vista os perigos a rondar "a musa popular do Norte", exposta à "invasão estrangeira", que, valendo-se da "indiferença nacional", "vai levando por diante impunemente a sua obra de alteração do nosso caráter", ${ }_{15}$ conforme escreveu no pequeno ensaio "Um verso popular", publicado na Ilustração Brasileira. Enquanto, aqui, "indiferença" passa a ser sinônimo da falta de proteção, cuidado para com a poesia popular brasileira, em outro texto, "A poesia popular", editorial de fevereiro de 1878 , "indiferença" significa desvalorização da poesia popular, motivo da perda de tesouros preciosos:

Pretendemos unicamente lavrar nestas páginas um protesto contra a indiferença que entre nós se vota aos monumentos deste gênero que nos deixaram nossos antepassados.

Quantos não se perderam já, quantos não se perdem dia a dia, à míngua de quem os enfeixe, e lhe dê forma e organização perdurável? ${ }^{16}$

Era o que Franklin Távora se propôs a fazer, trazendo a público na revista de Henrique Fleiuss o resultado de suas pesquisas junto à "musa popular do Norte", oito contos reunidos sob o título "Lendas e tradições populares do Norte", ${ }_{17}$ "pálido aceno diante da grandeza do cancioneiro popular que se encontrava espalhado pelo

Idem, n. $35,1^{\circ}$ dez. 1877, p. 173.

Idem, n. 23, fev. 1878, p. 224.

17 A relação compreende as seguintes "lendas e tradições populares", publicadas na Ilustração Brasileira: "O sino encantado", idem, n. 13, $1^{\circ}$ jan. 1877, p. 202-3; "A visão da Serra Aguda", idem, n. 14, 15 jan. 1877, p. 215-8; “O tesouro do rio", idem, n. 15, $1^{\circ}$ fev. 1877, p. 230; “A cruz-do-patrão”, idem, n. 17, $1^{\circ}$ mar. 1877, p. 268-9; "Chora menino", idem, n. 18, 15 mar. 1877, p. 282; "As mãos do Padre Pedro Tenório", idem, n. 20, 15 abr. 1877, p. 310; "O cajueiro do frade", idem, n. 21, $1^{\circ}$ maio 1877, p. 334-5; "As mangas de jasmim”, idem, n. $23,1^{\circ}$ jun. 1877, p. 359 e 363.

Teresa revista de Literatura Brasileira [12|13]; São Paulo, p. 130-143, 2013 • 137 
Brasil”, na avaliação de Cláudio Aguiar. ${ }^{18}$ Talvez por isso, Távora tenha se concentrado nas lendas populares pernambucanas, relacionadas ao tempo da invasão dos holandeses em Pernambuco, no século Xvir. Essas lendas são aquelas que, "resistindo à ação destruidora do tempo, puderam chegar até nossos dias", uma vez que a "poesia dos selvagens [...] correu a refugiar-se nas selvas interiores, onde dia por dia se foi extinguindo até que de todo desapareceu com o último da última horda”. ${ }^{19}$ Este lamento do narrador do conto "A cruz-do-patrão" não impede de interpretar o repertório de lendas populares organizado por Távora como expressão da dívida do Brasil para com o Norte, pois foram bravos nortistas como Matias de Albuquerque, Felipe Camarão, André de Negreiros que, lutando ao lado dos portugueses, contra os batavos, chamados "hereges" no conto "O sino encantado", livraram o país de cair em poder da Holanda.

A história do domínio holandês nas províncias do Norte do Brasil justifica a musa do Norte não cantar a "poesia do lar", tão somente a poesia da guerra, na qual repercutiam "a voz dos trabucos e arcabuzes, o som dos clarins, o retintim dos terçados e adagas dos conquistadores e conquistados, dignos uns dos outros". ${ }^{20} \mathrm{O}$ passado épico de Pernambuco nobilita a história da província, o mesmo acontecendo com as lendas ligadas ao período da dominação batava, ou antes, por contiguidade, a história enobrece a lenda e esta se transforma na memória popular da história. Assim, o que permaneceu na lembrança do povo quanto à passagem dos holandeses por Porto de Pedras ficou conhecido como o caso do sino encantado, que uma velha do lugarejo vai contar ao narrador:

- [...] Contam os antigos que antes de se render esta vila àqueles excomungados, os cristãos, sabendo que eles tinham por costume fazer das igrejas de Deus casas de malefícios, tiram dos altares todas as imagens, e da torre o sino; as imagens foram repartidas por entre o povo batizado, e o sino foi trazido ao rio e afundado no lugar, que lhe mostrei. Meu dito, meu feito. Os pés-de-pato, assim que tomaram conta da terra fizeram da igreja fortaleza, para guerrearem contra a cristandade. Mas depois foram batidos, e tiveram de fugir. ${ }^{21}$

18 AGUIAR, Cláudio. Franklin Távora e o seu tempo. Op. cit., p. 261.

19 Ilustração Brasileira, n. 17, $1^{\circ}$ mar. 1877, p. 268.

20 Idem.

21 Idem, n. 13, $1^{\circ}$ jan. 1877, p. 202.

138 - AZEVEDO, Sílvia Maria. Romantismo brasileiro e a "musa popular do Norte" 
Igualmente contíguos estão a lenda e o conto moral, que ainda a história do sino encantado permite ilustrar: quando os holandeses foram embora, o vigário do local prometeu tirar o sino do rio, mas nunca que fazia. Um dia, um menino tomava banho no Manguaba e deu com o sino, que a muito custo foi retirado da água. $\mathrm{O}$ padre e o juiz começaram a discutir quanto ao local em que devia ser colocado. Nisto, as cordas se partiram e o sino caiu de novo no rio, afundou na lama e nunca mais ninguém o viu. A partir de então, as pessoas de Porto de Pedras passaram a ouvir badaladas que vinham de dentro do rio, sempre ao meio-dia e à meia-noite, a lembrar não mais a passagem dos holandeses pelo local, mas a ambição dos homens.

0 fato de ter colhido esta história diretamente da fonte, isto é, junto à moradora do lugarejo, é garantia para o narrador de que a história contada ao leitor não foi inventada nem por ele, nem pela velha, como vai dizer no fecho do conto: "Assim se despediu a velha, a quem devo este conto, que não é invenção minha, e que depois de me ter sido assim narrado, eu verifiquei não ser também invenção da velha, mas uma tradição alagoana, que tem consagração de muitos anos". ${ }^{22}$

Compreendem-se as suspeitas em relação à invenção, pois refletem o rebaixamento da imaginação como princípio maior da atividade criadora, segundo a estética romântica, a observação da realidade tornando-se o principal fator da criação romanesca, durante a década de 1870 no Brasil.

Assim como os romances de Távora, baseados em personagens e episódios tomados da história, a garantir "exatidão daguerreotípica", na interpretação que o escritor fazia da obra de Cooper, também os contos populares recriados têm ancoragem, primeiramente na história, para depois migrarem para a lenda em diálogo com o conto moral, como acontece em "Chora Menino". A história se passa em 1635, numa tarde de junho em que uma "multidão, de velhos trôpegos, mulheres desgrenhadas, crianças seminuas", chega ao Recife, vinda do Forte Real do Bom Jesus. Sitiado durante três meses, o forte acabou por cair em poder das tropas holandesas. Tendo passado por muitas privações, aquela multidão mais parecia "múmias repugnantes" do que seres humanos. Dentre aquelas pessoas, duas mulheres destacavam-se, Ana e Lourença de Sousa, ambas trazendo nos braços os filhos que choravam de fome e de sede. Não resistindo ao cansaço, as duas irmãs morrem, e também as crianças. A partir de então, o lugar passou a se chamar Chora Menino, sendo tido por mal-as- 
sombrado: "Dizia o povo, harpa sonora em que vibram os mistérios da noite e da solidão, que quem passava por ali ouvia chorar menino". ${ }^{23}$

As marcas do passado heroico de Pernambuco estão por toda parte, tanto no mundo da natureza, árvores, rios, mangues, quanto no mundo da cultura, logradouros públicos, monumentos, registrando histórias de levantes e superstições, no relato de contos como "O tesouro do rio", "As mãos do padre Tenório" e "A cruz-do-patrão". O primeiro narra um fato que se deu no Recife, ao tempo do Brasil colônia, quando morava na cidade um bando de negociantes ricos, que não sabiam o que fazer com tanto dinheiro. Enquanto isso, os soldados morriam de fome, situação que os levou a liderar insurreição que guiou para as ruas "mangas de homens famintos de pão, sedentos de justiça". As vítimas eram os moradores mais afamados, que da noite para o dia ficaram pobres: "Tesouros infinitos passaram dos seios e mãos das filhas e mães, com os que foram arrancados dos cofres dos pais de famílias, para o poder das turbas desenfreadas". ${ }^{24}$ Alguns dos tesouros roubados foram enterrados numa das ilhotas do rio Beberibe, que muitos anos mais tarde atraíram um canoeiro que em sonho vislumbrou os cofres enterrados. Acontecia, porém, que, todas as vezes que o canoeiro começava a cavar, um vento forte obrigava-o a parar, até que ele se deu conta de que era a Providência que procurava afastá-lo de alguma desgraça, pois o tesouro enterrado no mangue era amaldiçoado.

Já "As mãos do padre Tenório" tem localização histórica mais precisa, pois se refere ao envolvimento do padre Pedro de Sousa Tenório no movimento da proclamação da República, em Pernambuco, em 6 de março de 1817. Debelada a insurreição, o vigário foi condenado ao suplício capital, a forca e o esquartejamento, o governo português tendo mandado colocar em praça pública o poste onde se fixaram as mãos do padre Tenório, e na ilha de Itamaracá, um outro onde ficou exposta a sua cabeça, "para exemplo e lição de todos os que a ele se sentissem presos por laços que os pudessem arrastar a crime igual ao seu". Um dia, duas crianças que brincavam perto do lugar onde o vigário de Itamaracá fora enforcado viram uma luz azul que emanava de suas mãos, do tamanho e no formato da hóstia consagrada. A partir de então, os moradores do local compreenderam que aquela luz significava a alma do padre Tenório que, depois da morte, foi considerado santo e milagreiro: “- Queres

23 Idem, n. 18, 15 mar. 1877, p. 282.

24 Idem, n. 15, $1^{\circ}$ fev. 1877, p. 230. 
achar o teu objeto perdido? Pega-te com a alma do padre Tenório. Promete-lhe um Padre-Nosso e uma Ave-Maria". 25

Da mesma forma que o povo escolhia os seus heróis, dentre os quais o Cabeleira, cujas façanhas eram cantadas pela "musa popular do Norte", ele escolhia também os seus santos, e com ambos se identificava, visto representarem, conforme Franklin Távora diz no posfácio do romance, "alguma virtude grande, a que o sentimento do justo, inato no coração do povo, não é indiferente". ${ }^{26}$ Por outro lado, na medida em que esses contos populares são expressão do passado de luta de Pernambuco, talvez se pudesse dizer que eles vinham alertar o Sul de que as províncias do Norte poderiam vir a se rebelar novamente, agora contra o governo imperial, caso este continuasse a mantê-las à margem dos melhoramentos da civilização.

$\mathrm{Na}$ recriação das lendas populares do Norte, tal como acontece em "O cajueiro do frade", é possível ouvir também ecos do envolvimento de Franklin Távora na "questão dos bispos", ao tempo em que dirigia o jornal A Verdade, do Recife. Na longa introdução que precede a narrativa, o narrador diz ter conhecido, na Praia de São José da Coroa Grande, o "cajueiro do frade", e outro, na capital pernambucana, de nome "cajueiro do bispo", experiência a fundamentar suas reflexões em torno da hierarquia católico-eclesiástica, que vê inscrita na "mesma família vegetal". O "cajueiro do frade" representa o humilde servo de Deus, que percorre "solidões infinitas", "lugares inóspitos", "regiões havidas por intransponíveis", a levar a "palavra singela do Evangelho". O "cajueiro do bispo" simboliza o "aristocrático funcionário" da Igreja, aquele que "pertenceu quase sempre à cidade", o prelado envolvido em concílios, na administração das dioceses, quando não em questões mais políticas do que religiosas.

Estabelecido o confronto entre o "plebeu", o frade, e o "patrício", o bispo, tem início a história que dá nome ao conto. Designado para servir no interior de Pernambuco, frei José decidiu que sua casa seria debaixo de um cajueiro. Em pouco tempo, outras casas humildes começaram a ser construídas no lugar, dando origem a uma pequena comunidade. Um dia, o frade é chamado de volta ao seu convento, para tristeza do povo, que começou a vê-lo passeando e rezando ao anoitecer, como sempre fazia. Alguns anos depois, frei José morre, e tem início a lenda do "cajueiro do frade": o vulto do saudoso sacerdote começou a ser visto pelos moradores, rondando o lugar, que passou a ser mal-assombrado, poucas pessoas tendo coragem de chegar perto:

25 Idem, n. 20, 15 abr. 1877, p. 310.

26 TÁVORA, Franklin. O Cabeleira. Op. cit., p. 138.

Teresa revista de Literatura Brasileira [12|13]; São Paulo, p. 130-143, 2013 • 141 
Para fazerem medo às crianças falam-lhes muito as velhas do frade sem cabeça e da manga onde costuma meter os meninos chorões ou mal-ouvidos. [Itálico no original.] ${ }^{27}$

"A cruz-do-patrão" é outro conto que leva no título o nome de um lugar maldito, a cruz de pedra, colocada no alto de elevada coluna, entre Recife e Olinda, para orientar os navegantes. Com o tempo, o marco histórico ficou associado a "tradições de espíritos infernais e bruxarias", representadas pelos congressos anuais dos feiticeiros negros do Recife, celebrados nas noites de São João. Como de praxe, à meia-noite, "o rei das trevas" baixou entre os mandingueiros, na descrição do narrador, que conseguiu construir um ser realmente assustador:

Tinha a forma de um animal desconhecido. Era preto como carvão. Os olhos acessos despediam chispas azuis. Brasas vivas caíam-lhe da boca escancarada e ameaçadora. Pela garganta se lhe viam as entranhas, onde o fogo fervia. A visão horripilante a todos meteu medo. ${ }^{28}$

Entre as pessoas que tinham ido tomar mandinga [itálico no original], encontrava-se uma negra "de grosso toutiço e largas ancas, que lhe davam a forma de tanajura" [itálico no original]. Foi a vítima escolhida pelo espírito do mal, que se atirou sobre ela. A duras penas, a mulher conseguiu escapar e correu pela praia, até a Cruz do Patrão. O diabo, no entanto, não lhe deu trégua, obrigando a negra a meter-se pelos mangues. No dia seguinte, no lugar do corpo da mulher foi encontrada a Coroa preta [itálico no original], a indicar a vingança do espírito das trevas: "Dizia o povo que, quando houvesse desaparecido de todo a Coroa preta, teria cessado também o encanto da Cruz do Patrão". ${ }^{29}$

Hoje já não se falava mais nem na coroa, nem na cruz, mesmo porque, naqueles tempos em que as superstições davam lugar a mentes ilustradas, esclarecidas pela ciência, ninguém mais tinha medo do lugar, frequentado apenas pelos soldados que vigiavam as fortalezas. Também não era mais necessário, para ir do Recife a Olinda, usar aquele caminho. A estrada de ferro de Santo Amaro viera ligar as duas cidades,

27 Ilustração Brasileira, n. 21, $1^{\circ}$ maio 1877, p. 334

28 Idem, n. $17,1^{\circ}$ mar. 1877, p. 268.

29 Idem. 
"as locomotivas enchendo [...] a margem direita do Beberibe de fumos e ruídos que indicam o percurso da civilização por aquelas solidões pitorescas"..30

Pobre "musa popular do Norte"! O que será de ti quando os teus bandidos e assombrações não meterem medo a mais ninguém? Só te restará migrar para o Sul, envergar luxuosa toilette, tomar um tílburi e entrar no Alcazar para assistir a uma opereta de Offenbach, tão em moda nos palcos da Corte carioca, naquela época.

Sílvia Maria Azevedo é professora do Departamento de Literatura, UnEsP-Assis, com Bolsa de Produtividade em Pesquisa/cNPq. Atua nas áreas de Teoria Literária, Literatura Brasileira e Literatura Comparada. Principais publicações: Brasil em imagens. Um estudo da revista Ilustração Brasileira (1876-8). São Paulo: Editora da UNESP, 2011; História de quinze dias, História de trinta dias. Crônicas de Machado de Assis - Manassés. Organização, prefácio e notas de Sílvia Maria Azevedo. São Paulo: Editora da UNESP, 2011; Paul Valéry. Meu Fausto. Introdução, tradução e notas de Lídia Fachin e Sílvia Maria Azevedo. São Paulo: Ateliê, 2011.

30 Idem, n. 17, p. 268.

Teresa revista de Literatura Brasileira [12|13]; São Paulo, p. 130-143, 2013 • 143 